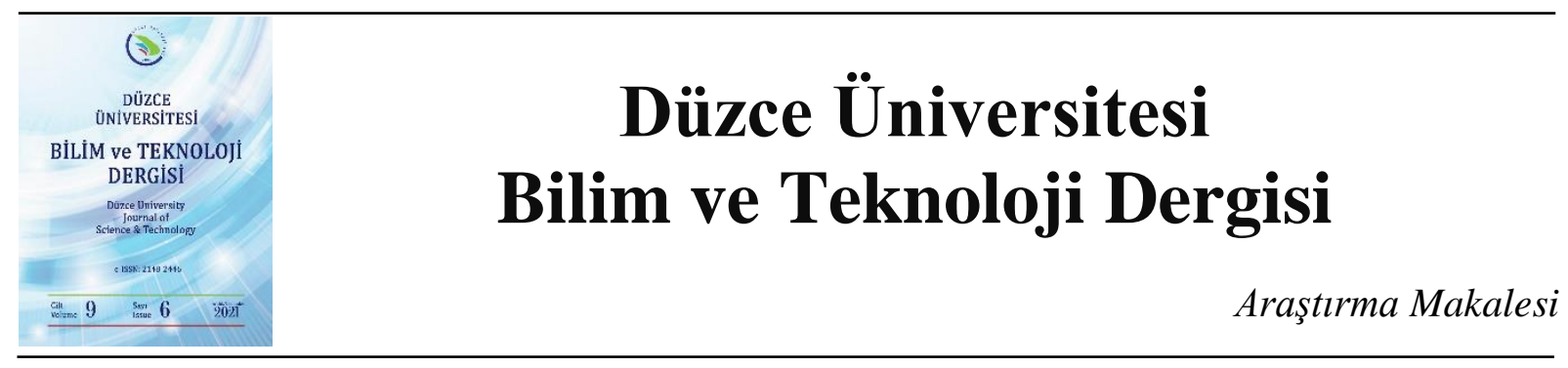

\title{
Makine Öğrenmesi Modelleri ile Ön lisans Öğrencilerinin Hangi Lise Türünden Mezun Olduklarının Tahmin Edilmesi ${ }^{1}$ \\ (D) Hüseyin KÜÇÜKERDEM ${ }^{\mathrm{a}, *}$, (D) Yusuf SÖNMEZ ${ }^{\mathrm{b}}$, (D) Cemal YILMAZ ${ }^{\mathrm{c}}$, (D) Hasan Hüseyin SAYAN ${ }^{\mathrm{a}}$ \\ ${ }^{a}$ Elektrik Elektronik Mühendisliği Bölümü, Teknoloji Fakültesi, Gazi Üniversitesi, Ankara, TÜRKIYYE \\ ${ }^{b}$ Bilgisayar Teknolojileri ve Siber Güvenlik Bölümü, Bilgi ve Haberleşme Teknolojileri Fakültesi, Azerbaycan \\ Teknik Üniversitesi, Bakü, AZERBAYCAN \\ ${ }^{c}$ Mingeçevir Devlet Üniversitesi, Mingeçevir, AZERBAYCAN \\ * Sorumlu yazarin e-posta adresi: hkucukerdem@ankara.edu.tr
}

DOI: 10.29130/dubited.1011190

\begin{abstract}
$\underline{\mathrm{OZZ}}$
Çalışmanın kapsamını, makine öğrenmesinde sık kullanılan algoritmalardan olan; tree, random forest, logistic regression ve linear regression teknikleri ile iki ayrı sınıftan oluşan öğrenci grubunun hangi lise türünden mezun olduklarına yönelik tahminde bulunma örneği oluşturmaktadır. Ön lisans elektronik ve otomasyon bölümünde okuyan bu öğrenci sınıflarından ilki elektronik haberleşme teknolojisi diğeri ise elektronik teknolojisi programı sınıfıdır. Sinıflandırmada belirleyici rol üstlenen beş ders seçilmiştir. Bu derslerden bazıları lise eğitiminde ortak görülen dersler olurken bazıları ise meslek lisesinin elektrik elektronik programlarında okutulan meslek derslerden oluşmaktadır. Örnek uygulamada öncelikle algoritma davranış farklılıklarının gözlemlenmesi hedeflenmiştir ve buna ek olarak da öğrencilerin farklı liselerden gelmiş olmaları bir kısım derste kendini başarı/başarısızlık olarak ortaya çıkarıyor mu? Sorunsalına cevap bulmaktır.
\end{abstract}

Anahtar Kelimeler: Makine Ögrrenmesi, Random Forest Algoritmasl, Lojistik Regresyon Algoritmasl, Tree Algoritma.

\section{With Machine Learning Models Estimating Which High School Types Associate Degree Students Have Graduated \\ ABSTRACT}

In this study, by using three of the machine learning algorithms, a group of students studying in the associate degree electronic communication technology program, is it a vocational high school of the type of high school they graduated? or is it a high school other than vocational high school? Has been estimated. Considering the grade point end of term averages from the five courses determined during the associate degree process, the type of high school they came from was estimated. Two of these determined courses are courses close to the courses taught in vocational high schools and three are general courses taught in all high schools. Aim; It is to reveal how accurately three different machine learning algorithms make predictions on the same sample. In addition, it is foreseen that the pre-professional knowledge of normal high school students who are placed in vocational high school-based associate degree programs will be determined, and necessary precautions will be taken.

Keywords: Machine Learning, Random Forest Algorithm, Logistic Regression Algorithm, Tree Algorithm.

\footnotetext{
${ }^{1}$ ICAIAME 2021 konferansında sunulmuş olup, özet metin olarak basılmıştır.

Geliş: 18/10/2021, Düzeltme: 03/12/2021, Kabul: 11/12/2021
} 


\section{GIRIS}

Ölçme, Seçme ve Yerleştirme Merkezi (ÖSYM) tarafindan 2016 yılında son kez uygulanarak yürürlükten kaldırılan, "Meslek Lisesi Mezunu Öğrencilerinin Önlisans Programlarına Sınavsız Geçiş Uygulaması" sonrasında özellikle meslek lisesi haricindeki liselerden mezun olan öğrencilerinde önlisans mesleki programlara başvuruları artmaya başlamıştır. Son yıllarda önlisans programlarında açılan genel kontenjanlara başvuru ve yerleştirme sayıları baz alındığında, meslek lisesi mezunu öğrencilerinin oranlarında hızlı düşüşler gözlemlenmektedir. Önlisans mesleki programlara yerleşen adaylar örgün eğitim sürecine geçip derslere başladıklarında bazı derslerde ayrışmalar yaşandığı gözlemlenmektedir. Örnek verilecek olursa; Meslek lisesinden mezun olmuş öğrencilerin önlisans derslerine ait sınav sonuçları incelendiğinde, genel ortak derslerde normal liselerden (Anadolu Lisesi, Fen Lisesi vb.) mezun olmuş önlisans öğrencilerine göre daha başarısız oldukları gözlemlenmiştir. Benzer şekilde normal Anadolu veya fen liselerinden mezun olmuş önlisans öğrencilerinin önlisans derslerine ait sınav sonuçları incelendiğinde, programa ait meslek derslerinde meslek lisesi mezunu önlisans öğrencilerine göre daha başarısız oldukları gözlemlenmiştir. Gözlemlenen bu durumlar ise her iki öğrenci grubunda da bazı derslerde ön hazırlık gerekliliğini doğurmaktadır. Bu sebepten dolayı bu örnek çalışma yapılmış ve gözlem sonuçları değerlendirilmiştir.

Literatürde alanla ilgili çalışmalar incelendiğinde; [2]'de, üniversite öğrencilerinin genel başarı ortalamalarının tahmini için Yapay Sinir Ağları yöntemi kullanılmıştır. [3]'de ise Türkiye'de yükseköğretimde ilk yıl öğrencilerinin akademik performansına etki eden faktörlerin araştırılması ve bu faktörlere bağlı olarak başarılarının tahminine yönelik Random Forest yöntemi temelli bir karar destek sistemi tasarımı gerçekleştirilmiştir. [4]'de, lise öğrencilerinin ders başarımları Tree Algoritma yöntemi ile tahmin edilmiştir. [5]'de, çevrimiçi özel ders sisteminden ABD'nin 8. sınıf matematik testlerine ait bilgiler toplanmış ve bireysel becerilere bağlı test puanları Naive Bayes ağları kullanılarak tahmin edilmiştir. [6]'da, Portekiz'de iki ortaokulda yapılan anket çalışmaları sonucunda elde edilen veriler üzerinde Naive Bayes algoritması kullanılarak öğrencilerin ders notları tahmin edilmiştir. Tüm bu çalışmalarda kullanılan özniteliklerin farklılıkları yanı sıra çalışmaların uygulandıkları ülkenin sosyokültürel ve sosyoekonomik ölçütleri de öğrenci akademik başarımında rol oynamaktadır. [1]

Elektronik Haberleşme Teknolojisi Önlisans Programı birinci sınıf öğrencilerinin ilk dönemlerine ait beş ayrı dersin vize ve final not ortalamaları baz alınarak uygulama örneği gerçekleştirilmiştir. Baz alınan beş Genel Ortak Dersler şunlardır; Genel Matematik, Türk Dili 1 ve Temel Yabancı Dil 1 (İngilizce), Önlisans Programına ait Alan Dersleri; Elektronik 1 ve Doğru Akım (DC) Devre Analizi şeklindedir. Bu derslerin seçilmesindeki amaç program alan derslerinde normal liseden gelen öğrencilerin eksiklerinin, genel ortak derslerde ise meslek lisesinden gelen öğrencilerin eksiklerinin ortaya çıkarılarak bu durumların olumsuz yönlerini tespit ederek ortadan kaldırmaya yönelik çalışmaların yapılmasıdır. İlk dönem (güz) elde edilen sınav sonuçları kullanılarak makine öğrenmesi uygulaması gerçekleştirilmiş ve aynı yıl benzer önlisans programına (Elektronik Teknolojisi) yerleşen öğrencilerin yine ilk dönem sinav sonuçlarına göre hangi lise türünden geldikleri makine öğrenmesi ile tespit edilmiştir. Bu uygulama örneğinde Tree, Logistic Regression ve Random Forest algoritmaları kullanılmış ve uygulama sonuçlarına göre kıyaslamaları yapılmıştır.

\section{YÖNTEMLER}

\section{A. VERİ SETİ}

$\mathrm{Bu}$ çalışmada kullanılan veri seti, Ankara Üniversitesi Elmadağ Meslek Yüksekokulu Elektronik Haberleşme Teknolojisi Önlisans Programı 1. Sınıf öğrencilerine ait 2020 güz dönemi vize ve final not ortalamalarından elde edilmiştir. Veri seti 20 ögrencinin 5 ayrı dersten aldıkları vize ve final notlarının ortalamaları kullanılarak oluşturulmuştur. 


\section{B. VERİ ÖZELLIKKLERİ}

İki adet veri seti kullanılmıştır. Bunlardan birinci veri seti Elektronik Haberleşme Programı 1. Sınıf ögrencilerinden 20 tanesinin 5 ayrı dersin vize ve final notlarının toplamlarının yarısı alınarak oluşturulmuştur. Ayrıca öğrenciler 2 ana kategoride gruplandırılmıştır. Bunlar "Meslek Lisesi" ve meslek lisesi dışı yani "Normal Lise" şeklindedir. Birinci veri setine ait öznitelikler Tablo 1'de görülmektedir.

Tablo 1. Elektronik Haberleşme Teknolojisi Programı 1. Sinıf ögrencilerinin (1. veri seti) güz döneminde 5 ayrı dersten aldlklarl vize ve final notlarinin ortalamast.

\begin{tabular}{llccccc}
\hline Ad Soyad & Lise Türü & Matematik & İngilizce & DC Devre & Elektronik & Türk Dili \\
\hline Yasin Gü* & Meslek & 45 & 64 & 75 & 78 & 72 \\
\hline Salih Do* & Normal & 87 & 85 & 70 & 73 & 98 \\
\hline Efe E. Er* & Meslek & 50 & 45 & 85 & 80 & 76 \\
\hline Samet Y1* & Meslek & 60 & 71 & 90 & 88 & 71 \\
\hline Gaye Ak* & Meslek & 55 & 65 & 75 & 85 & 65 \\
\hline Yunus U1* & Meslek & 40 & 55 & 77 & 75 & 74 \\
\hline Hazar Ak* & Meslek & 70 & 45 & 83 & 85 & 76 \\
\hline Mert Du* & Normal & 81 & 95 & 80 & 40 & 85 \\
\hline Mutlu Y1* & Normal & 92 & 90 & 55 & 70 & 88 \\
\hline Ahmet Or* & Meslek & 45 & 55 & 95 & 90 & 76 \\
\hline Mücahit Do* & Normal & 95 & 95 & 45 & 55 & 95 \\
\hline Yusuf Ü1* & Normal & 85 & 100 & 60 & 35 & 90 \\
\hline Baran Du* & Meslek & 40 & 65 & 95 & 85 & 45 \\
\hline Selin Y1* & Meslek & 55 & 70 & 78 & 80 & 55 \\
\hline Bilal At* & Normal & 78 & 86 & 50 & 15 & 90 \\
\hline Kaan Ay* & Normal & 85 & 85 & 35 & 75 & 83 \\
\hline Ahmet E. Gü* & Meslek & 45 & 50 & 75 & 85 & 79 \\
\hline Utku Gü* & Normal & 80 & 100 & 45 & 60 & 95 \\
\hline Furkan Er* & Meslek & 45 & 60 & 79 & 77 & 72 \\
\hline Emre Y* & Meslek & 30 & 35 & 76 & 80 & 68 \\
\hline
\end{tabular}

Kullanılan iki adet veri setinden ikinci veri seti ise aynı bölümün diğer programı olan Elektronik Teknolojisi 1. Sınıf öğrencilerinden 20 tanesinin 5 ayrı dersin vize ve final notlarının toplamlarının yarısı alınarak oluşturulmuştur. $\mathrm{Bu}$ veri setinde ise okul türleri tahmin edildiği için veri setinde yer verilmemiştir. İkinci veri setine ait öznitelikler Tablo 2'de görülmektedir. 
Tablo 2. Elektronik Teknolojisi Programı 1. Sını öğrencilerinin (2. veri seti) güz döneminde 5 ayrı dersten aldiklarl vize ve final notlarını ortalamast.

\begin{tabular}{lcccccc}
\hline Ad Soyad & Lise Türü & Matematik & İngilizce & DC Devre & Elektronik & Türk Dili \\
\hline Burak Hö* & $?$ & 45 & 75 & 75 & 78 & 70 \\
\hline Yunus E. Ko* & $?$ & 80 & 85 & 45 & 65 & 90 \\
\hline Naci Ar* & $?$ & 72 & 45 & 85 & 80 & 65 \\
\hline Samet Ca* & $?$ & 60 & 40 & 90 & 95 & 75 \\
\hline Eren Çe* & $?$ & 55 & 65 & 75 & 85 & 70 \\
\hline Emre Du* & $?$ & 18 & 22 & 65 & 63 & 58 \\
\hline Musa Er* & $?$ & 71 & 45 & 65 & 75 & 51 \\
\hline İlhami Ko* & $?$ & 83 & 95 & 35 & 79 & 67 \\
\hline Görkem Ko* & $?$ & 92 & 95 & 55 & 77 & 83 \\
\hline Kamile Ac* & $?$ & 15 & 25 & 86 & 91 & 60 \\
\hline Dilşad Be* & $?$ & 98 & 75 & 75 & 62 & 70 \\
\hline Nusret Ç1* & $?$ & 40 & 42 & 53 & 87 & 95 \\
\hline Atifet Do* & $?$ & 71 & 63 & 58 & 89 & 70 \\
\hline İkbal Gö* & $?$ & 85 & 82 & 78 & 92 & 65 \\
\hline Büşra N. Ka* & $?$ & 45 & 48 & 62 & 50 & 78 \\
\hline Tuncay Ke* & $?$ & 20 & 25 & 45 & 67 & 50 \\
\hline Onur Mü* & $?$ & 80 & 85 & 78 & 92 & 100 \\
\hline Hamdi Sa* & $?$ & 50 & 64 & 71 & 45 & 60 \\
\hline Kadir So* & $?$ & 20 & 32 & 45 & 50 & 50 \\
\hline Görkem Ön* & $?$ & 45 & 48 & 63 & 89 & 60 \\
\hline & & & & & & \\
\hline
\end{tabular}

\section{DENEYLERDE KULLANILAN ALGORITMALAR}

Bütün deneylerde Orange Data Mining 3.28.0 programı kullanılmıştır. Veri setleri üzerinde Tree, Logistic Regression, Random Forest ve Karar Ağacı (Tree) algoritmaları uygulanmıştır.

\section{BULGULAR VE TARTISMMA}

Yapılan örnek uygulama deneyinde iki ayrı programın birer sınıflarına ait beş ayrı dersin sınav sonuçları kullanılarak oluşturulan eğitim veri seti, Şekil 1'de görülen program giriş vidget'larına uygulanmıştır. Bunlardan birinci veri seti olan Elektronik Haberleşme Programı grubundaki öğrencilerin mezun oldukları lise türleri bilgileri yine birinci veri setinde algoritma akışına uygulanmıştır. Birinci veri seti; Tree, Logistic Regression ve Random Forest algoritmalarında kullanılarak öğrenme gerçekleştirilmiştir. 


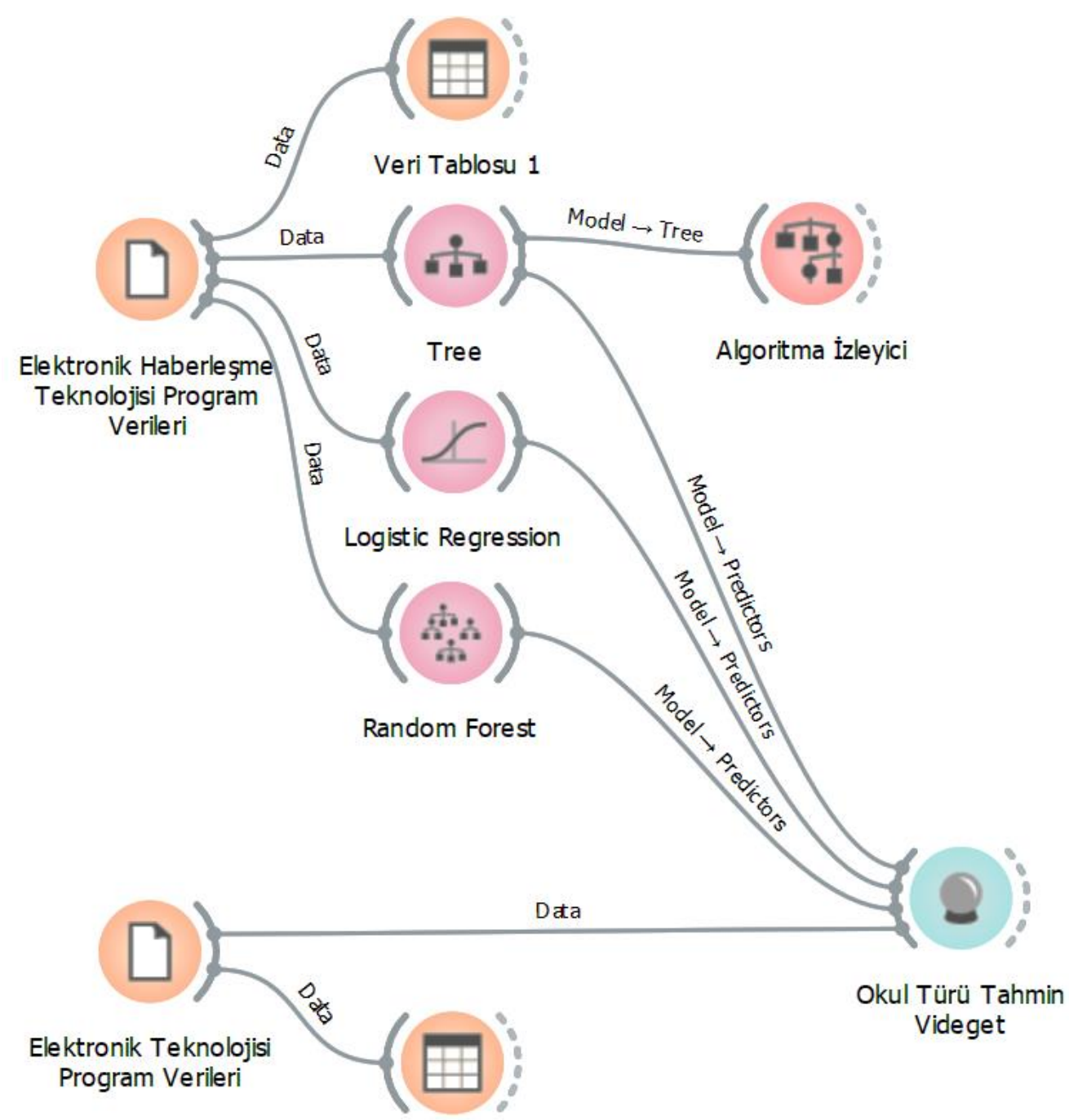

Veri Tablosu 2

Şekil 1. Makine öğretimi için kullanılan Elektronik Haberleşme Teknolojisi Programı ve tahmin için kullanılan Elektronik Teknolojisi Programı veri setlerinin uygulandiğı program arayüzü.

Birinci veri setine ait bilgilerin programa tanıtıldıktan sonraki Data Tablo görüntüsü Tablo 3 'te verilmiştir. Tablo 3'te Matematik dersine ait verilerin yer aldığ 1 sütun incelendiğinde 20. Sirada yer alan öğrencinin notu derecelendirmeye program tarafından dahil edilmemiştir. Bunun nedeni Matematik dersine ait sınıf ortalaması Şekil 7'degörüldügü üzere 48,33'tür ve ortalamanın ölçek aralığı \pm 10 'dur. Yani 38,33'ün altında kalan öğrenciler program tarafından derecelendirmeye dahil edilmemiştir.

Benzer şekilde Doğru Akım Devre Analizi not ortalaması Şekil 6'da görüldüğü üzere 55'tir ve ölçek aralığ $\pm 13,7$ 'dir. Yani 41,3'ün altında kalan notlar derecelendirmeye dahil edilmemiştir. Benzer durumlar diğer dersler içinde geçerlidir. Bir sınıfın tamamının ortalaması hesaplandığı için Meslek Lisesi veya Normal Lise ayrılmadan en düşük ortalamaya göre değerlendirme yapılmaktadır. 
Tablo 3. Makine öğretimi için kullanılan Elektronik Haberleşme Teknolojisi Program verilerinin (referans ĕgitim seti) veri tablosu izlencesi.

\begin{tabular}{|c|c|c|c|c|c|c|c|}
\hline & Mes-Nor & İsim & Matematik & Yabancı Dil 1 & $\begin{array}{l}\text { Doğru Akım } \\
\text { Devre Analizi }\end{array}$ & Elektronik 1 & Türk Dili 1 \\
\hline 1 & Meslek & Yasin Gü* & 45 & 64 & 75 & 78 & 72 \\
\hline 2 & Normal & Salih Do* & 87 & 85 & 70 & 73 & 98 \\
\hline 3 & Meslek & Efe E. Er ${ }^{*}$ & 50 & 45 & 85 & 80 & 76 \\
\hline 4 & Meslek & Samet $Y_{I^{*}}$ & 60 & 71 & 90 & 88 & 71 \\
\hline 5 & Meslek & Gaye $\mathrm{Ak}^{\dot{x}}$ & 55 & 65 & 75 & 85 & 65 \\
\hline 6 & Meslek & Yunus UI* & 40 & 55 & 77 & 75 & 74 \\
\hline 7 & Meslek & Hazar Ak & 70 & 45 & 83 & 85 & 76 \\
\hline 8 & Normal & Mert Du* & 81 & 95 & 80 & 40 & 85 \\
\hline 9 & Normal & Mutlu $Y_{I^{*}}$ & 92 & 90 & 55 & 70 & 88 \\
\hline 10 & Meslek & Ahmet Or* & 45 & 55 & 95 & 90 & 76 \\
\hline 11 & Normal & Mücahit Do* & 95 & 95 & 45 & 55 & 95 \\
\hline 12 & Normal & Yusuf Ül & 85 & 100 & 60 & 35 & 90 \\
\hline 13 & Meslek & Baran Du* & 40 & 65 & 95 & 85 & 45 \\
\hline 14 & Meslek & Selin $Y_{I^{*}}$ & 55 & 70 & 78 & 80 & 55 \\
\hline 15 & Normal & Bilal At* & 78 & 86 & 50 & 15 & 90 \\
\hline 16 & Normal & Kaan $\mathrm{Ay}^{\ddot{*}}$ & 85 & 85 & 35 & 75 & 83 \\
\hline 17 & Meslek & Ahmet E. Gü* & 45 & 50 & 75 & 85 & 79 \\
\hline 18 & Normal & Utku Güi & 80 & 100 & 45 & 60 & 95 \\
\hline 19 & Meslek & Furkan $\mathrm{Er}^{*}$ & 45 & 60 & 79 & 77 & 72 \\
\hline 20 & Meslek & Emre $Y_{1^{*}}$ & 30 & 35 & 76 & 80 & 68 \\
\hline
\end{tabular}

Tablo 4. Makine öğretimi için kullanılan Elektronik Haberleşme Teknolojisi Programı ve tahmin için kullanılan Elektronik Teknolojisi Programı veri setlerinin algoritmalara uygulandıktan sonra, her üç algoritma için Meslek Lisesi tahmin dereceleri.

\begin{tabular}{|c|c|c|c|c|c|c|c|c|c|}
\hline & Tree & Logistic Regression & Random Forest & Ad Soyad & Matematik & Yabancı Dil 1 & DC Devre Analizi & Elektronik 1 & Türk Dili 1 \\
\hline 1 & $1.00 \rightarrow$ Meslek & $1.00 \rightarrow$ Meslek & $1.00 \rightarrow$ Meslek & Burak Hö* & 45 & 75 & 75 & 78 & 70 \\
\hline 2 & $0.00 \rightarrow$ Normal & I $0.01 \rightarrow$ Normal & $0.00 \rightarrow$ Normal & Yunus E. Ko* & 80 & 85 & 45 & 65 & 90 \\
\hline 3 & $0.00 \rightarrow$ Normal & $1.00 \rightarrow$ Meslek & $0.91 \rightarrow$ Meslek & Naci Ar & 72 & 45 & 85 & 80 & 65 \\
\hline 4 & $1.00 \rightarrow$ Meslek & $1.00 \rightarrow$ Meslek & $1.00 \rightarrow$ Meslek & Samet $\mathrm{Ca}^{\star}$ & 60 & 40 & 90 & 95 & 75 \\
\hline 5 & $1.00 \rightarrow$ Meslek & $1.00 \rightarrow$ Meslek & $1.00 \rightarrow$ Meslek & Eren Çe $\mathrm{e}^{\star}$ & 55 & 65 & 75 & 85 & 70 \\
\hline 6 & $1.00 \rightarrow$ Meslek & $1.00 \rightarrow$ Meslek & $0.91 \rightarrow$ Meslek & Emre Du* & 18 & 22 & 65 & 63 & 58 \\
\hline 7 & $0.00 \rightarrow$ Normal & $1.00 \rightarrow$ Meslek & $\underline{0.82 \rightarrow \text { Meslek }}$ & Musa Er* & 71 & 45 & 65 & 75 & 51 \\
\hline 8 & $0.00 \rightarrow$ Normal & I $\underline{0.09} \rightarrow$ Normal & $\underline{0.18} \rightarrow$ Normal & İlhami Ko* & 83 & 95 & 35 & 79 & 67 \\
\hline 9 & $0.00 \rightarrow$ Normal & I $0.00 \rightarrow$ Normal & $\underline{0.09} \rightarrow$ Normal & Görkem Ko* & 92 & 95 & 55 & 77 & 83 \\
\hline 10 & $1.00 \rightarrow$ Meslek & $1.00 \rightarrow$ Meslek & $1.00 \rightarrow$ Meslek & Kamil Ac* & 15 & 25 & 86 & 91 & 60 \\
\hline 11 & $0.00 \rightarrow$ Normal & I $0.02 \rightarrow$ Normal & $\underline{0.64 \rightarrow \text { Meslek }}$ & Dilşad Be $e^{*}$ & 98 & 75 & 75 & 62 & 70 \\
\hline 12 & $1.00 \rightarrow$ Meslek & $1.00 \rightarrow$ Meslek & $0.91 \rightarrow$ Meslek & Nusret Çı* & 40 & 42 & 53 & 87 & 95 \\
\hline 13 & $0.00 \rightarrow$ Normal & I $0.99 \rightarrow$ Meslek & $\underline{0.91 \rightarrow \text { Meslek }}$ & Atifet Do* & 71 & 63 & 58 & 89 & 70 \\
\hline 14 & $0.00 \rightarrow$ Normal & I $\underline{0.62 \rightarrow \text { Meslek }}$ & $\underline{0.18} \rightarrow$ Normal & İkbal Gö* & 85 & 82 & 78 & 92 & 65 \\
\hline 15 & $1.00 \rightarrow$ Meslek & $1.00 \rightarrow$ Meslek & $0.91 \rightarrow$ Meslek & Büşra N. Ka* & 45 & 48 & 62 & 50 & 78 \\
\hline 16 & $1.00 \rightarrow$ Meslek & $1.00 \rightarrow$ Meslek & $0.91 \rightarrow$ Meslek & Tuncay Ke ${ }^{\star}$ & 20 & 25 & 45 & 67 & 50 \\
\hline 17 & $0.00 \rightarrow$ Normal & I $0.04 \rightarrow$ Normal & $\underline{0.09} \rightarrow$ Normal & Onur Mü* & 80 & 85 & 78 & 92 & 100 \\
\hline 18 & $1.00 \rightarrow$ Meslek & $0.99 \rightarrow$ Meslek & $\underline{0.91 \rightarrow \text { Meslek }}$ & Hamdi Sa* & 50 & 64 & 71 & 45 & 60 \\
\hline 19 & $1.00 \rightarrow$ Meslek & $1.00 \rightarrow$ Meslek & $0.91 \rightarrow$ Meslek & Kadir So* & 20 & 32 & 45 & 50 & 50 \\
\hline 20 & $1.00 \rightarrow$ Meslek & $1.00 \rightarrow$ Meslek & $1.00 \rightarrow$ Meslek & Görkem Ön* & 45 & 48 & 63 & 89 & 60 \\
\hline
\end{tabular}

Elektronik Teknolojisi Programına ait grubun beş dersten aldıkları sınav sonuçlarına ait veri seti Şekil 1 'de görülen arayüze ait programa tanıtılmıştır. Tanıtım sonrası gerçekleşen öğrenme sonucuna göre algoritmaların Meslek Lisesi tahminlerine ait derecelendirmeler Tablo 4'te, Normal Liseleri tahminlerine ait derecelendirmelerde Tablo 5'te verilmiştir. 
Tablo 5. Makine öğretimi için kullanılan Elektronik Haberleşme Teknolojisi Programı ve tahmin için kullanılan Elektronik Teknolojisi Programı veri setlerinin algoritmalara uygulandıktan sonra, her üç algoritma için Normal Lise tahmin dereceleri.

\begin{tabular}{|c|c|c|c|c|c|c|c|c|}
\hline Tree & Logistic Regression & Random Forest & Ad Soyad & Matematik & Yabancı Dil 1 & DC Devre Analizi & Elektronik 1 & Türk Dili 1 \\
\hline $0.00 \rightarrow$ Meslek & $0.00 \rightarrow$ Meslek & $0.00 \rightarrow$ Meslek & Burak Hö* & 45 & 75 & 75 & 78 & 70 \\
\hline $1.00 \rightarrow$ Normal & $0.99 \rightarrow$ Normal & $1.00 \rightarrow$ Normal & Yunus E. Ko* & 80 & 85 & 45 & 65 & 90 \\
\hline$\underline{1.00 \rightarrow \text { Normal }}$ & $0.00 \rightarrow$ Meslek & $\underline{0.09} \rightarrow$ Meslek & Naci $\mathrm{Ar}^{\star}$ & 72 & 45 & 85 & 80 & 65 \\
\hline $0.00 \rightarrow$ Meslek & $0.00 \rightarrow$ Meslek & $0.00 \rightarrow$ Meslek & Samet $\mathrm{Ca}^{\star}$ & 60 & 40 & 90 & 95 & 75 \\
\hline $0.00 \rightarrow$ Meslek & $0.00 \rightarrow$ Meslek & $0.00 \rightarrow$ Meslek & Eren Ç $\mathrm{e}^{*}$ & 55 & 65 & 75 & 85 & 70 \\
\hline $0.00 \rightarrow$ Meslek & $0.00 \rightarrow$ Meslek & $\underline{0.09} \rightarrow$ Meslek & Emre Du* & 18 & 22 & 65 & 63 & 58 \\
\hline $1.00 \rightarrow$ Normal & $0.00 \rightarrow$ Meslek & $\underline{0.18} \rightarrow$ Meslek & Musa $\mathrm{Er}^{*}$ & 71 & 45 & 65 & 75 & 51 \\
\hline$\underline{1.00 \rightarrow \text { Normal }}$ & $0.91 \rightarrow$ Normal & $\underline{0.82 \rightarrow \text { Normal }}$ & İlhami Ko* & 83 & 95 & 35 & 79 & 67 \\
\hline$\underline{1.00 \rightarrow \text { Normal }}$ & $1.00 \rightarrow$ Normal & $\underline{0.91 \rightarrow \text { Normal }}$ & Görkem Ko* & 92 & 95 & 55 & 77 & 83 \\
\hline $0.00 \rightarrow$ Meslek & $0.00 \rightarrow$ Meslek & $0.00 \rightarrow$ Meslek & Kamil $A C^{*}$ & 15 & 25 & 86 & 91 & 60 \\
\hline$\underline{1.00 \rightarrow \text { Normal }}$ & $0.98 \rightarrow$ Normal & $\underline{0.36 \rightarrow \text { Meslek }}$ & Dilşad Be* & 98 & 75 & 75 & 62 & 70 \\
\hline $0.00 \rightarrow$ Meslek & $0.00 \rightarrow$ Meslek & $\underline{0.09 \rightarrow \text { Meslek }}$ & Nusret Çı ${ }^{\star}$ & 40 & 42 & 53 & 87 & 95 \\
\hline $1.00 \rightarrow$ Normal & $0.01 \rightarrow$ Meslek & $\underline{0.09} \rightarrow$ Meslek & Atifet Do* & 71 & 63 & 58 & 89 & 70 \\
\hline $1.00 \rightarrow$ Normal & $0.38 \rightarrow$ Meslek & $\underline{0.82 \rightarrow \text { Normal }}$ & İkbal Gö* & 85 & 82 & 78 & 92 & 65 \\
\hline $0.00 \rightarrow$ Meslek & $0.00 \rightarrow$ Meslek & $\underline{0.09 \rightarrow \text { Meslek }}$ & Büşra N. Ka* & 45 & 48 & 62 & 50 & 78 \\
\hline $0.00 \rightarrow$ Meslek & $0.00 \rightarrow$ Meslek & $\underline{0.09} \rightarrow$ Meslek & Tuncay $\mathrm{Ke}^{\star}$ & 20 & 25 & 45 & 67 & 50 \\
\hline$\underline{1.00 \rightarrow \text { Normal }}$ & $0.96 \rightarrow$ Normal & $\underline{0.91 \rightarrow \text { Normal }}$ & Onur $\mathrm{Mü}^{*}$ & 80 & 85 & 78 & 92 & 100 \\
\hline $0.00 \rightarrow$ Meslek & $0.01 \rightarrow$ Meslek & $\underline{0.09} \rightarrow$ Meslek & Hamdi Sa* & 50 & 64 & 71 & 45 & 60 \\
\hline $0.00 \rightarrow$ Meslek & $0.00 \rightarrow$ Meslek & $\underline{0.09} \rightarrow$ Meslek & Kadir So* & 20 & 32 & 45 & 50 & 50 \\
\hline $0.00 \rightarrow$ Meslek & $0.00 \rightarrow$ Meslek & $0.00 \rightarrow$ Meslek & Görkem Ön* & 45 & 48 & 63 & 89 & 60 \\
\hline
\end{tabular}

Tablo 5 incelendiğinde 7. ve 13. Stradaki öğrencilerin lise türleri Tree algoritma tarafından diğer algoritmalardan farklı olarak değerlendirilmiş ve bu değerlendirmeleri hatalı olarak şekil 2 (a)'da ayrıca görülmektedir. Bu durumun nedeni 3. Satır için Matematik dersine ait not ve 7. Satır için Doğru Akım Devre Analizi dersine ait nottur.

Normal Lise 1, Meslek Lisesi 0 değeriyle derecelendirilmiştir. Yani Meslek lisesi için derecesi 0 olan satırların kesinliği çok yüksektir, benzer şekilde Normal Liseler için derecesi 1 olan satırların kesinliği çok yüksektir.

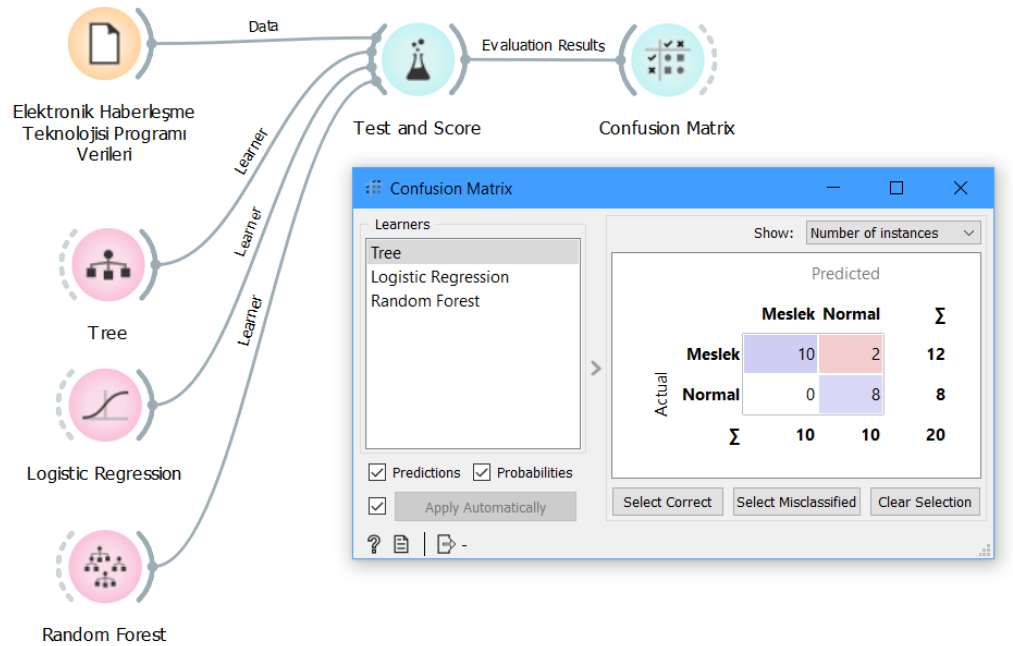

(a) 


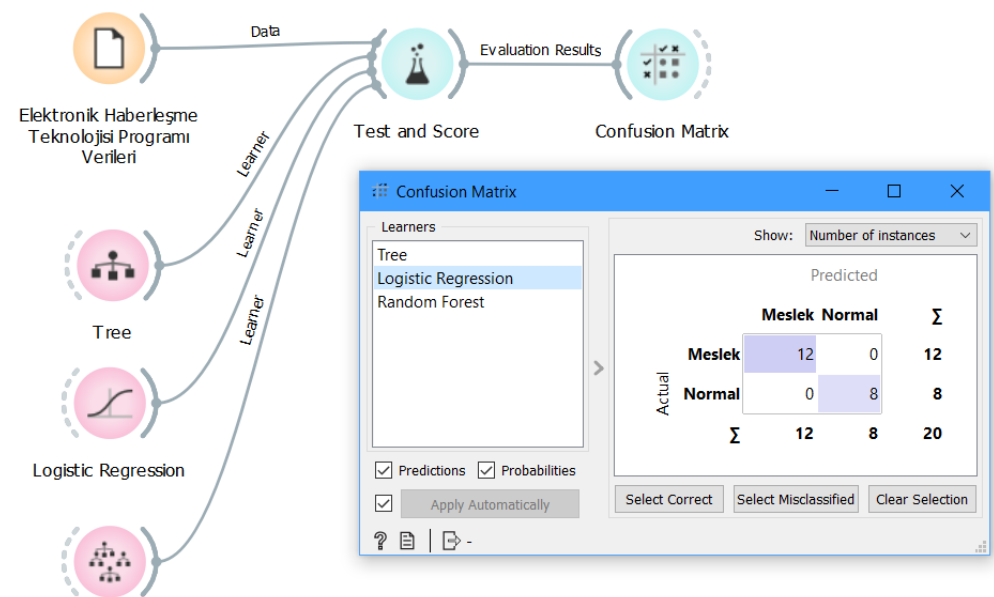

Random Forest

(b)

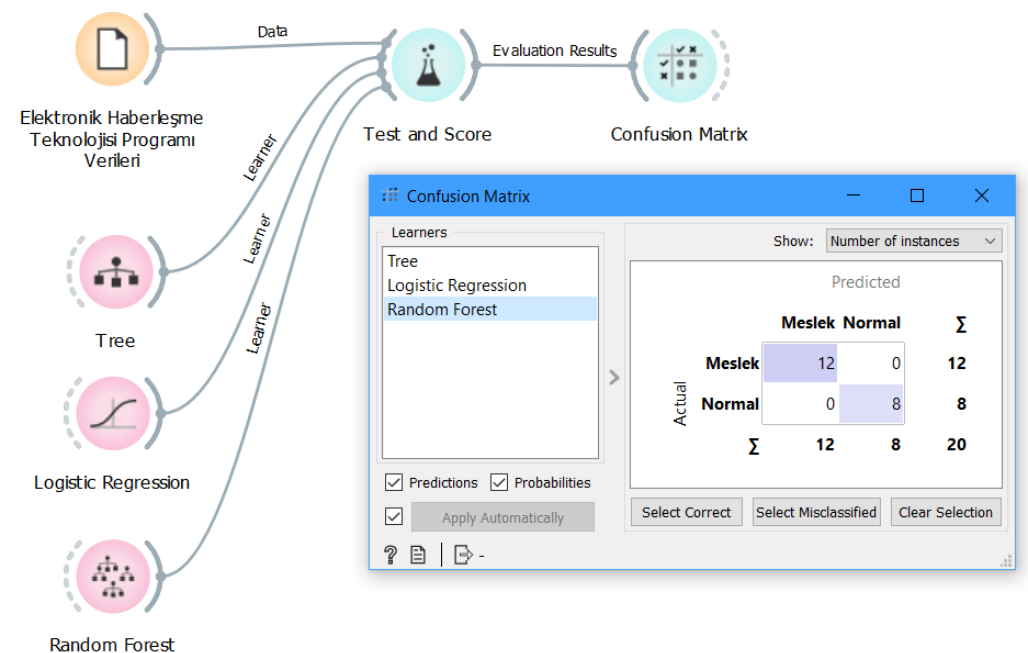

(c)

Şekil 2. Makine öğretimi için kullanılan Elektronik Haberleşme Teknolojisi veri setinin uygulandı̆̆ algoritmalarin kiyaslanmasl. (a) Tree, (b) Logistic Regression, (c) Random Forest.

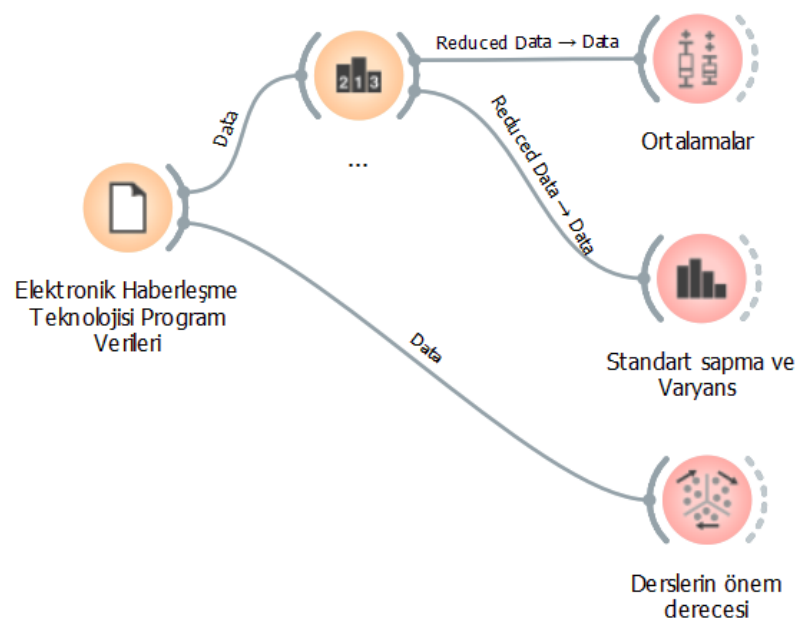

Şekil 4. Makine öğretimi için kullanılan Elektronik Haberleşme Teknolojisi veri setindeki derslerin ortalama, standart sapma, varyans ve önem derecelerinin incelendiği program arayüzü. 
Derslerin önem dereceleri ve belirleyicilik özellikleri konusunda Şekil 4'te arayüzü görülen program oluşturulmuştur. Burada derslere ait Meslek Lisesi ve Normal Liselerden mezun öğrencilerin bulundukları sınıfların ayrı ayrı not ortalamaları çıkarılmış ve Şekil 6 ve Şekil 7'de görülmektedir. Daha sonra sınıf notlarının standart sapmaları ve varyansları çıkarılmıştır ve şekil 8.a ve 8.b'de verilmiştir. Son olarak da derslerin önem ve belirleyicilik dereceleri ortaya çıkarılarak buna ait açısal etki grafiği Şekil 5'te verilmiştir.

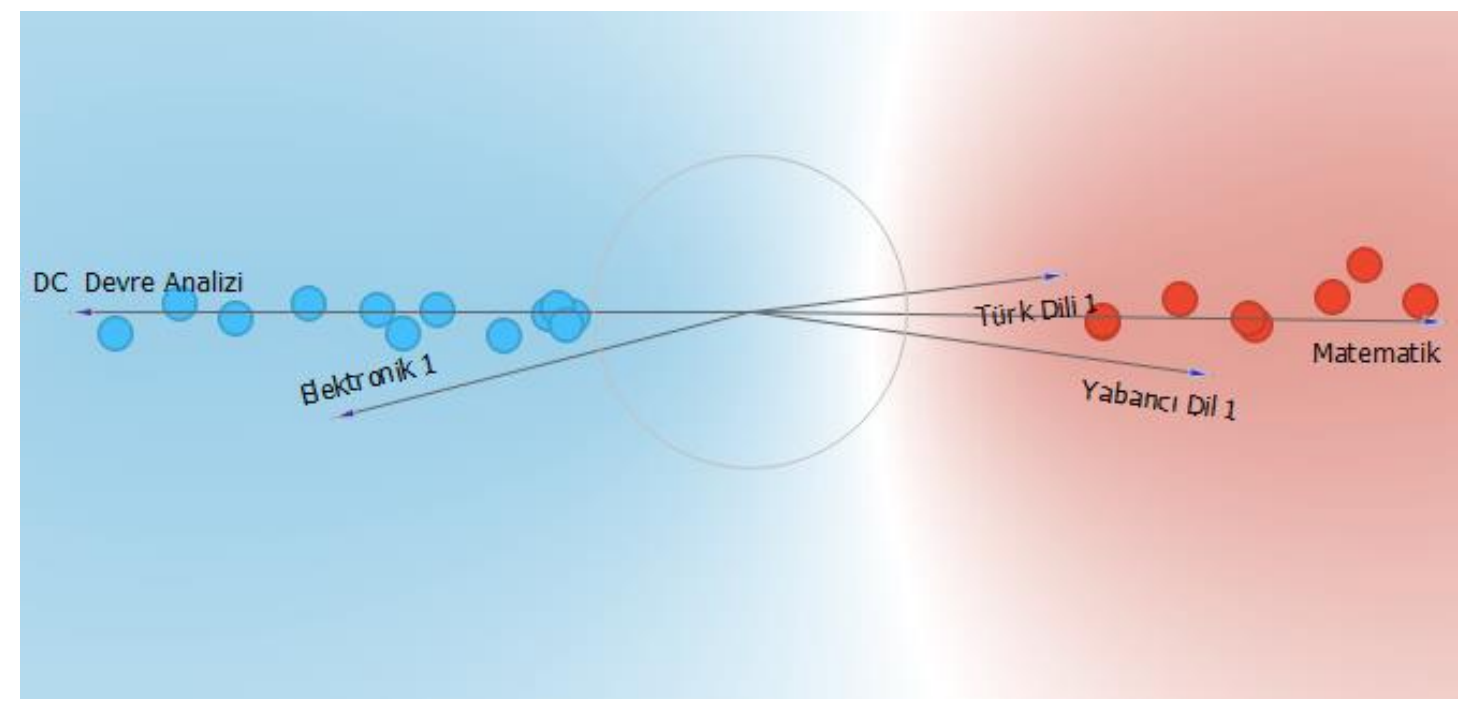

Şekil 5. Makine öğretimi için kullanılan Elektronik Haberleşme Teknolojisi Program veri setindeki derslerin önem dereceleri.

Şekil 5'te görüldüğü üzere Meslek Lisesinden mezun olmuş öğrencilerin veri setlerine göre en önemli belirleyici ders DC (Doğru Akım) Devre Analizi iken Normal Liseler için ise bu ders Matematiktir. Diğer derslerin belirleyici etkileri ise bu iki derse göre daha düşüktür.

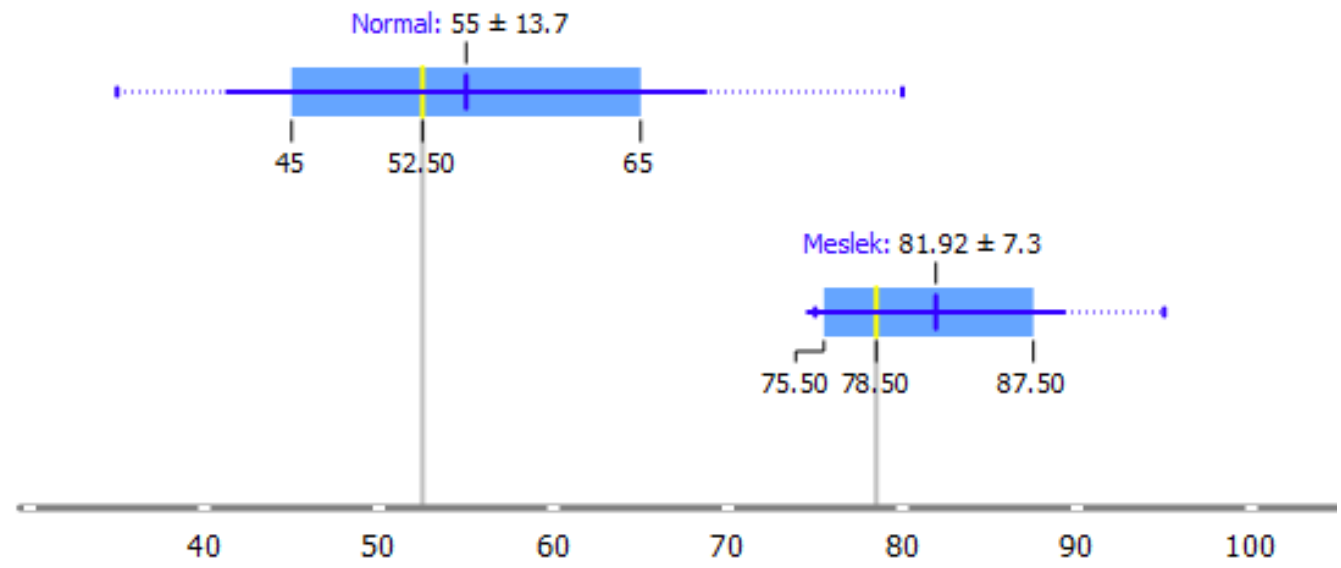

Şekil 6. Doğru Akım (DC) Devre Analizi dersine ait Meslek Lisesi ve Normal Lise grubunun ortalamalart.

Meslek Lisesi için en önemli belirleyici ders DC (Doğru Akım) Devre Analizi olduğu için sadece bu derse ait analiz grafiklerine yer verilmiştir. Benzer şekilde Normal Liseler için en önemli belirleyici ders Matematik olduğu için sadece bu derse ait analiz grafiklerine yer verilmiştir. 


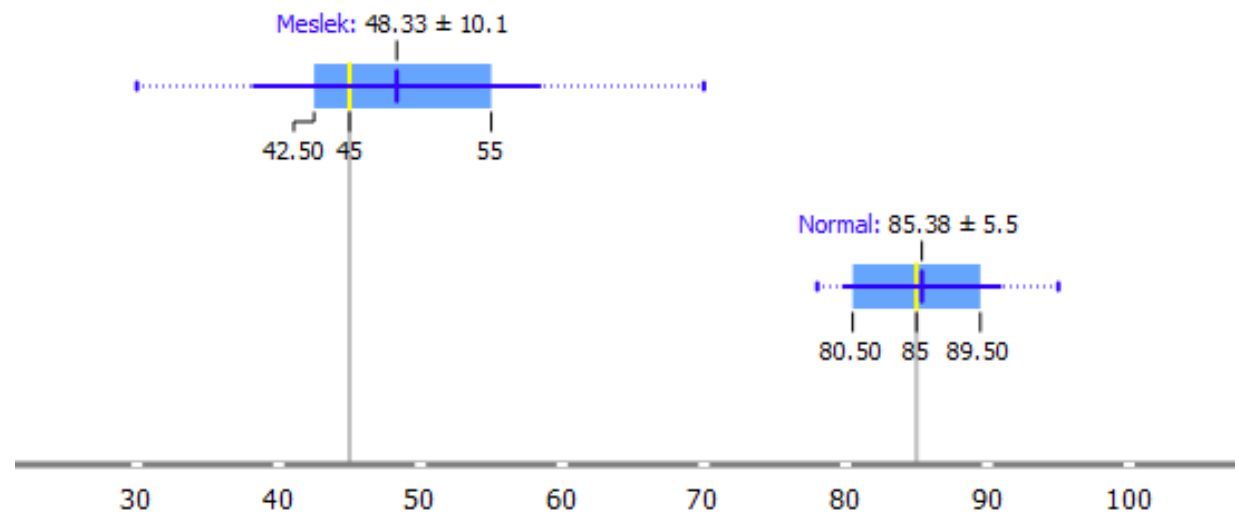

Şekil 7. Matematik dersine ait Meslek Lisesi ve Normal Lise grubunun ortalamalart.

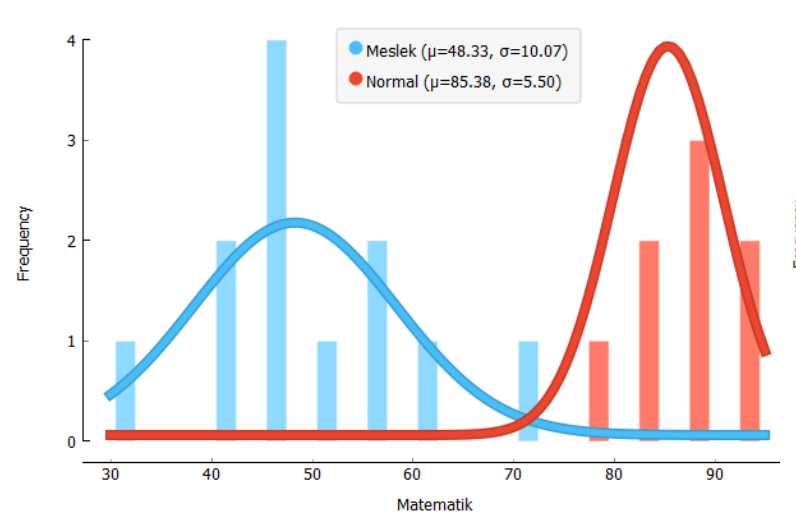

(a)

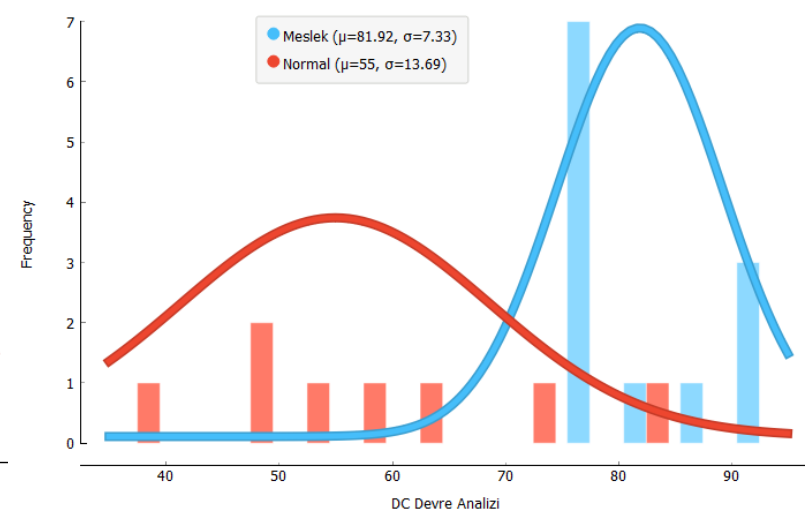

(b)

Şekil 8. (a) Matematik dersine ait Meslek Lisesi ve Normal Lise grubunun Standart Sapma ( $\mu$ ) ve Varyansını ( $\sigma)$ gösteren frekans grafiği, (b) Doğru Akım Devre Analizi dersine ait Meslek Lisesi ve Normal Lise grubunun Standart Sapma $(\mu)$ ve Varyansını ( $\sigma)$ gösteren frekans grafiği.

\section{IV.SONUC}

Eğitim, toplumların geleceğini şekillendiren en önemli standartlardan biridir. Teknik Eğitim ve Teknik eleman ihtiyacını karşılayan önlisans programları ise bu yolda önemli istasyonlardandır. Önlisans programlarına meslek lisesinden mezun olarak gelmiş öğrencilerin Anadolu Lisesi, Fen Lisesi gibi okullardan gelen öğrencilere göre kısmen temel derslerde daha yetersiz olduğu gerçeği bilinmektedir. Bu probleme dikkat çekme adına oluşturulmuş bu örnek uygulama deneyinde elde edilen sonuçlar bu çalışmada verilmiştir. Algoritmalara uygulanan ve bilinen birinci eğitim veri setinde 12 Meslek Lisesi ögrencisi varken 8 tanede Normal Lise mezunu öğrenci bulunmaktadır. 20 öğrenci üzerinden tanıtılan bu veri setine göre sadece Tree Algoritma 2 veriyi hatalı olarak öğrenmiş ve değerlendirmiştir. Meslek Lisesinden mezun olmuş öğrencilerin en az zorlandıkları ders Doğru Akım Devre Analizi olurken Normal Liselerden gelen öğrencilerin en az zorlandıkları ders Matematik olmuştur. Türk dili 1 dersi bütün mezunlar içerisinde en az zorlanılan ders olmasından dolayı belirleyiciliği en düşük ders olmuştur.

Sonraki süreçlerde gerçekleştirilecek çalışmalarda diğer algoritma yöntemleri denenebilir. Ayrıca deneylerde öğrenci sayısı artırılabilir. Aynı deney önlisans programlarına yeni yerleşmiş öğrencilerin birinci sınıfa başladıkları ilk dönemin hemen başında yapılacak bir ön seviye belirleme sınavı ile yapılarak öğrencilerin yetersizlik durumlarına göre kısa süreli hızlandırılmış destek eğitimi verilerek eğitim sorunu azaltılabilir. Ya da ayrı gruplara bölünerek eksik olunan kısımlara göre ek derslerle iki ayrı grup aynı seviyeye getirilebilir. 


\section{KAYNAKLAR}

[1] M. Gök, "Makine Öğrenmesi Yöntemleri ile Akademik Başarının Tahmin Edilmesi," Gazi Üniversitesi Fen Bilimleri Dergisi, c. 5, s. 3, ss. 139-148, 2017.

[2] D. Şengür, “Öğrencilerin Akademik Başarılarının Veri Madenciliği Metotları ile Tahmini,” Doktora Tezi, Bilgisayar ve Öğretim Teknolojileri Eğitimi Anabilim Dalı, Eğitim Bilimleri Enstitüsü, Fırat Üniversitesi, Elazığ, Türkiye, 2013.

[3] T.C. Hakyemez, "ilk Yıl Öğrencilerinin Akademik Performansına Etki Eden Faktörlerin Araştırılması ve Bu Faktörlere Bağlı Olarak Başarılarının Tahminine Yönelik Bir Karar Destek Sistemi Tasarım," Yüksek Lisans Tezi, Yönetim Bilişim Sistemleri Anabilim Dalı, Sosyal Bilimler Enstitüsü, Sakarya Üniversitesi, Sakarya, Türkiye, 2015.

[4] Ş. Özdemir, "Eğitimde Veri Madenciliği ve Öğrenci Akademik Başarı Öngörüsüne İlişskin Bir Uygulama," Yüksek Lisans Tezi, Enformatik Anabilim Dalı, Fen Bilimleri Enstitüsü, İstanbul Üniversitesi, İstanbul, Türkiye, 2016.

[5] Z. A. Pardos, N. T. Heffernan, \& B. Anderson, C. L. Heffernan, "Using Fine-Grained Skill Models to Fit Student Performance with Bayesian Networks", Proceedings of the Workshop in Educational Data Mining held at the 8th International Conference on Intelligent Tutoring Systems, Taiwan, 2006.

[6] P. Cortez \& A. Silva, "Using Data Mining To Predict Secondary School Student Performance", Proceddings of 5th Annual Future Business Technology Conference, Porto, Portugal, 2008, pp. 5-12. 